\title{
Corey, Robin
}

La mente reaccionaria:

el conservadurismo

desde Edmund Burke

hasta Donald Trump

\section{$2^{a}$ ed. Estados Unidos:}

Oxford University Press Inc, 2019

ISBN: 978-84-949668-8-0

Franco Rubén Marozzi

Licenciado en Ciencia Política con

especialización en Administración Pública

(Universidad Nacional de Rosario)

Correo: franco.marozzi1@gmail.com
Marino José Antici

Licenciado en Ciencia Política con

especialización en Administración Pública,

Profesor de Historia (Universidad Nacional de

Rosario)

Correo: manticixxv@gmail.com 
Corey, Robin. La mente reaccionaria: el conservadurismo desde Edmund Burke hasta Donald Trump Franco Rubén Marozzi - Marino José Antici

Resumen

En la obra "La mente Reaccionaria:

El conservadurismo desde Edmund

Burke hasta Donald Trump", el teórico político norteamericano Corey Robin vuelve a analizar el fenómeno que constituye la ideología conservadora desde una perspectiva de izquierda. Define las bases de lo que se constituye en el pensamiento conservador a partir de analizar las obras de los ideólogos históricos del movimiento situándolos en su contexto particular. El autor nos lleva en un recorrido histórico que comienza con Edmund Burke y su lucha contra la Revolución Francesa, hasta el siglo XXI para analizar el estado de situación del Partido Republicano norteamericano y su principal figura actual, el presidente Donald Trump.

Palabras clave conservadurismo, reacción, izquierda, derecha
Abstract

In "The Reactionary Mind:

Conservatism From Edmund

Burke to Donald Trump", the

American political theorist Corey

Robin revisits the phenomenon

that constitutes conservative ideology from a leftist perspective. It defines the bases of what constitutes conservative thought from analyzing the works of the movement's historical ideologues, placing them in their particular context. The author takes us on a historical journey that begins with Edmund Burke and his fight against the French Revolution to the 21 st century to analyze the state of affairs of the American Republican Party and its main current figure, President Donald Trump.

Key words

conservatism, reaction, left, right 
Algunas de las preguntas más interesantes que los investigadores del campo de las ciencias sociales se han hecho a lo largo de los siglos, parten de la distinción clásica entre izquierda y derecha, entre revolución y contrarrevolución, entre reformadores y conservadores. Podríamos pensar que dichas categorías en disputa, que parecen provenir de la mismísima noche de los tiempos, encontraría ciertos límites en un mundo dinámico y cambiante como la era del globalismo pero aun las encontramos vivas y persistentes en prevalecer. Dentro de este debate es que se circunscribe la obra "La mente Reaccionaria: El conservadurismo de Edmund Burke a Donald Trump" del autor norteamericano Corey Robin. Para el autor, ideólogos de la derecha en principios tan diversos como Burke, Nietzche, Schimitt, Rand, Goldwater y Scalía no solo son matices dentro de un espectro político, sino que existe un hilo conductor ideológico y estratégico que los une en un movimiento común a lo largo de la historia.

El autor que nos presenta esta hipótesis es Corey Robin, profesor de ciencia política del Brooklyn College y en el Graduate Center (New York City University). La mayor parte de su producción ensayística se dedica al estudio anlítico de los movimientos de derecha, tema que el autor viene abordando hace más de una década. Ensayos políticos tales como: "Fear: The History of a Political Idea" (2006), "The Reactionary Mind: Conservatism from Edmund Burke to Sarah Palin" (2011), "The Enigma of Clarence Thomas" (2019) y la segunda edición de "The Reactionary Mind: Conservatism from Edmund Burke to Donald Trump" (2019). Graduado en la Universidad de Princeton en la carrera de Historia y culminando su doctorado en Ciencia Política por la Universidad de Yale, sus obras literarias han destacado en el mundo editorial recibiendo premios de la American Political Science Association y han generado fuertes controversias llegando a ser considerado la primera edición de "The Reactionary Mind" como el libro que predijo a Donald Trump.

Mientras que buena parte de la investigación académica de Robin se centra en el análisis de la derecha política el autor también ha escrito para periódicos y revistas sobre una variedad de asuntos de preocupación para la izquierda. Estos incluyen ensayos sobre las problemáti- 
cas contemporáneas de la izquierda, el ascenso de figuras como Bernie Sanders y Alexandra Ocacio Cortez, políticas laborales en el lugar de trabajo, cómo la izquierda debe recuperar el principio de la libertad y sobre grandes intelectuales como Hannah Arendt, Eric Hobsbawm, Cass Sunstein y Ta-Neshi Coates. Sus artículos principalmente han aparecido en The New Yorker, Harper's Magazine, The London Review of Books, New York Times y Washington Post.

El libro "La mente Reaccionaria: El conservadurismo desde Edmund Burke hasta Donald Trump" es publicado por la Oxford University Press (OUP). OUP es una de las casas editoriales más prestigiosas del mundo por su número de publicaciones editando cerca de 4.500 nuevas publicaciones al año. Como su nombre lo sugiere es parte de la Universidad de Oxford y se encuentra ubicada en el Reino Unido.

La rama norteamericana de la OUP se estableció en 1896 en el 91 de la Quinta Avenida principalmente para la distribución de Biblias Oxford en Estados Unidos. Su primera publicación original "The Life of Sir William Osler" ganó un premio Pullitzer en 1926 y desde ese momento ha publicado más de 14 títulos ganadores del mismo galardón. Progresivamente la editorial fue creando diferentes ramas y actualmente la OUP tiene presencia en Sudamérica, Asia, África e incluso posee un departamento de música y un museo propio en Oxford.

La editorial, mediante Oxford Journals, se ha convertido también en uno de los principales publicadores de revistas académicas tanto en las ciencias naturales como en las humanísticas. También es una de las primeras editoriales universitarias en publicar revistas académicas de acceso público y de las primeras en ofrecer sistemas híbridos que permiten a los lectores acceder a papers de autores sin cargo alguno online. La OUP es miembro de la Asociación de Editoriales de Acceso Público.

El trabajo de Robin es la segunda edición de un trabajo previo "The reactionary mind: Conservatism from Edmund Burke to Sarah Palin" también publicado con OUP. La primera edición del trabajo fue una publicación altamente controversial en los círculos académicos norteamericanos. 
Fue criticado en algunos medios como un intento de "predicar al coro", sobre simplificar los argumentos históricos de la derecha y la oposición entre derecha e izquierda como una simple reacción de una para con la otra. Pero pese a estas controversias iniciales entre los intelectuales de la derecha y la obra de 2011 la historia parece haber reivindicado parte de los argumentos del autor al punto que su obra ha sido descrita como el libro que predijo el ascenso de Donald Trump una vez que los hechos se fueron desenvolviendo.

El trabajo del Dr. Robin consiste en un estudio analítico del fenómeno del conservadurismo y su pensamiento político cuidándose de los problemas que existen en los estudios previos: la falta de una perspectiva comparada que estudia la relación entre los diferentes movimientos conservadores en los distintos países, la ausencia de una perspectiva histórica del movimiento y dificultad para establecer la particular especificidad del movimiento como política de reacción frente a las ideas de la izquierda.

En esencia en su segunda obra Robin retoma su método de análisis, no tanto criticando el movimiento, conservador sino buscando hacer un análisis histórico comprensivo de sus ideas a partir de la descripción del pensamiento de sus principales ideólogos, desde la obra original de Edmund Burke hasta Donald Trump en la actualidad. En los hechos fue la propia victoria de Trump en las elecciones de 2016 lo que motivó al autor de la necesidad de una revisión de su trabajo previo sobre el conservadurismo.

En su estructura el libro comienza con una descripción de los bloques de construcción que constituyen las bases de la ideología conservadora. Lo que el autor denomina un "manual básico" del pensamiento de derecha. Se examina contra qué reacciona la derecha, a qué se opone, que es lo que busca defender y cuál es su estrategia para oponerse.

Una primera hipótesis que esboza el autor en este apartado es que el conservadurismo se encarga de aportar un argumento consistente que justifique porqué debe impedirse que los estamentos más bajos ejerzan su voluntad independiente y porque deben de mantenerse sometidos al orden establecido. La sumisión es el primer deber de quie- 
nes se encuentran marginados y nada genera más preocupación en los conservadores que la vocación de los excluidos de participar de igual a igual dentro del ámbito público, en la provocación revolucionaria de cambiar la jerarquía social. Es decir, el problema no son tanto las ideas que proponen los movimientos que buscan la emancipación sino más bien su vocación por trastocar las jerarquías imperantes en la sociedad. Uno de los ejemplos más claros que expone la obra, la encontramos en los argumentos de la igualación de la mujer con el hombre y el obrero con el patrón, esta acción proveniente del universo reformista/revolucionario provoca la reacción de un amplio conjunto de elementos de la sociedad que ven puestos sus privilegios en discusión dentro del universo considerado privado como lo son la familia y la fábrica.

Sin embargo, el conservadurismo no es descrito como estático. Es un movimiento que constantemente busca renovarse y renovar a las clases dirigentes para que de esta manera se mantengan lo suficientemente vitales para ser capaces de resistir los movimientos emancipadores. Es así que autores conservadores como Edmund Burke critican a la nobleza británica que considera laxa e impotente y exaltan la vitalidad que para ellos representan circunstancias violentas como la guerra o el conflicto.

Una segunda hipótesis es que el conservadurismo no está determinado por las castas o las ideologías religiosas de quienes se caracterizan como conservadores incluso cuando se definan a sí mismos como tal. Está constituido por aquellos que se oponen a que los individuos se emancipan de sus superiores, especialmente en el ámbito privado.

Para Robin los conceptos tales como reaccionario, contrarrevolucionario y conservador son sinónimos que identifican a algo llamado derecha. El autor explica que el conservadurismo nace como reacción a la búsqueda de subvertir el orden establecido por movimientos de izquierda disruptivos del orden legitimado. De esta afirmación se desprende que el interés central del conservador no sea la propuesta de nuevas políticas sino la victoria en la esfera pública como medio para conservar las ventajas que ya poseen, a diferencia de los movimientos de izquierda que ven en la victoria política un medio para imponer su 
agenda de reformas. El conservador estaría dispuesto, en pos de conservar las jerarquías establecidas, en reconstruir el régimen imperante con tal de lograr el mantenimiento del orden jerárquico.

En análisis histórico que propone el autor nos permite ver los conflictos entre el espectro político de izquierda y el espectro político de derecha como un análisis y estudio por parte del último, acciones centradas en estrategias y metodologías, para lograr su primacía en su lucha contra el primero. Se percibe una toma de elementos de la izquierda, como el lenguaje, por ejemplo, por parte de la derecha para lograr que sus intereses sean vehiculizados en la sociedad. Ante los cambios de la izquierda, la derecha también lo hace.

En el segundo momento el libro pasa al análisis histórico propiamente dicho estudiando figuras relevantes para el movimiento ubicadas cronológica y geográficamente, compara sus ideologías y posicionamientos para luego explicitar en que, cada una aporta al movimiento conservador. Estas figuras tomadas aquí son especialmente importantes porque se ubican en momentos cronológicos de levantamientos contestatarios contra los cuales actúa la contrarrevolución (La guerra civil inglesa, la revolución francesa, la comuna de París y la revolución Bolchevique). Los ideólogos contrarrevolucionarios tomados por Robin son Hobbes, Burke, Nietzsche y Rand.

El análisis de las figuras históricas conservadoras (en su contexto) es uno de los aportes que nace de las críticas que el propio Robin hace a la manera en la que actualmente se estudia el conservadurismo. Tomar figuras históricas le permite al autor establecer comparaciones entre ellas, las ideas que expresan y defienden. También puede observarse un hilo conductor que comparten y aunque realiza juicios de valor en diversos momentos del análisis, el autor no hace de la crítica el punto central de cada apartado.

Finalmente, el trabajo finaliza llegado a la época moderna centrándose en el pensamiento político conservador anglosajón como el principal heredero de esta tradición histórica con importantes referentes como Goldwater, Scalía y Trump quienes encabezan movimientos que responden a conductas históricas. Es así que el populismo de Trump o la pasión a la hora de defender causas potencialmente 
perdidas del juez Antonin Scalía no son mostradas como acciones circunstanciales sino tácticas de combate político respaldados por años de ideología conservadora.

Trump es un sujeto histórico especialmente interesante para Robin ya que lo define como una ideología de la nada. El nuevo presidente con sus propuestas políticas se contradice a sí mismo una y otra vez, pero, sin embargo, siempre es capaz de mantener una promesa populista en sus enunciados. Como ideal conservador representa la fusión entre el burgués capitalista que se ha hecho a sí mismo y el político que enciende a las multitudes con discursos enardecidos en contra de los enemigos externos e internos de la nación.

Una de las críticas que podemos hacer a la obra de Corey Robin, como suele pasar con los intelectuales de la academia norteamericana, es que posee una visión occidentalista en su análisis de la tradición filosófica conservadora. Los ideólogos y ejemplos históricos tomados son norteamericanos o europeos, el modelo responde principalmente a las lógicas partidarias tradicionales de la democracia liberal. Aun así, a consecuencia de la abstracción que caracteriza el planteo de Robin, no es difícil tomar parte de las hipótesis planteadas y ser capaces de ver cómo se adaptan fácilmente a los fenómenos históricos tanto latinoamericanos como mundiales.

Sin embargo, la pluralidad y variedad que brinda la historia mundial dificulta la linealidad como explicación a los sucesos de interacción entre izquierdas y derechas, especialmente cuando se tienen en cuenta la compleja relación entre las elites establecidas y los estratos marginados. Por poner algunos ejemplos, ¿la revolución Meiji en el Japón del XIX es, poniendo en juego estas categorías ¿̇eforma o restauración? El movimiento Nardonik durante el mismo periodo en la Rusia zarista ¿es el primer socialismo o una forma conservadurismo de tinte popular? Estos movimientos ¿buscan otorgar derechos a los grupos marginados o salvar las estructuras de poder imperantes? ¿Se pueden combinar ambas cosas?

Si traemos estas categorías a nuestra historia nacional, nos encontramos con dificultades semejantes. Cuando la unión cívica radical se opuso a los gobiernos del partido autonomista nacional, ¿lo 
hacía como una fuerza revolucionaria o contrarrevolucionaria? Los radicales no plantean reemplazar o pervertir las estructuras sociales establecidas, ni el modelo económico imperante o el sistema político vigente. Buscaban que se cumpliera con la constitución nacional en la celebración de elecciones libres, ya que su acceso al gobierno se encontraba vedado. ¿Esto lo convierte en un partido conservador? ¿Su reforma implica que nuevos actores sociales tengan voz o "es cambiar para que nada cambie"?

Con el fenómeno del peronismo ocurre la misma cuestión, ¿es una fuerza de tipo revolucionaria o reaccionaria? Si sus orígenes lo situamos en la dictadura del 43', lo convierte en una fuerza reaccionaria a las decisiones tomadas por el gobierno de la concordancia, en relación al fraude electoral, la corrupción imperante y la política exterior ambivalente. Su reacción llega al punto de aplicar una política de reeducación de la sociedad argentina, basada en el nacionalismo católico y opuesto al liberalismo imperante hasta el momento. Pero es también considerada una fuerza que llevó adelante reformas que posibilitaron un cambio profundo en la estructura social argentina, modificando tanto las composiciones de las elites como sus valores y creencias, posibilitando el ascenso social de vastos sectores populares.

Como conclusión, podemos decir que la obra del Dr. Robin es un aporte interesante al análisis político vigente en cuanto a los criterios del pensamiento teórico conservador y qué constituye lo conservador desde una perspectiva de izquierda. Presenta limitaciones para explicar fenómenos históricos globales, pero su teoría está mejor adaptada en cuanto a comprender sucesos históricos que responden al arco conservador en los países occidentales, especialmente al funcionamiento del movimiento conservador norteamericano, la especialidad de Corey Robin. Su aplicabilidad a otras realidades para entender la mente conservadora, tanto latinoamericanas como también asiáticas o africanas, es una opción nada despreciable a los estudios faltantes del fenómeno de la derecha internacional.

Recepción: 22/04/2020

Aceptación: 10/09/2020 